\title{
Nasal endotracheal intubation in a premature infant with a nasal encephalocele
}

Department of Neurosurgery, Booth

Hospital, Charlestown

Road, Manchester M9

2AA

Carys M Bannister

M Kashab

H Dagestani

Department of

Paediatrics, Lancaster

Royal Infirmary

Monica Placzek

Correspondence to:

Dr Kashab.

Accepted 17 April 1993 Hall Children's

\begin{abstract}
After a difficult nasal intubation a premature infant leaked cerebrospinal fluid (CSF) from one nostril. After developing bacterial meningitis, the baby was referred for neurosurgical management of the CSF fistula. Transaxial computed tomograms demonstrated a nasal encephalocele, but coronal scans were needed to show the defect in the cribriform plate.

(Arch Dis Child 1993; 69: 81-82)
\end{abstract}

Nasal encephaloceles are rare in Western society but one should be aware of them because they can have serious consequences. External examination of the patient may reveal nothing as some of these encephaloceles are wholly concealed within the nasal air spaces. ${ }^{12}$ Nasal intubation poses a hazard in such cases, and the diagnosis should be thought of if the passage of an endotracheal tube through the nose is unusually difficult or accompanied by an unexpected event. We report the outcome of a difficult nasal endotracheal intubation in a premature infant who required ventilation for lung immaturity.

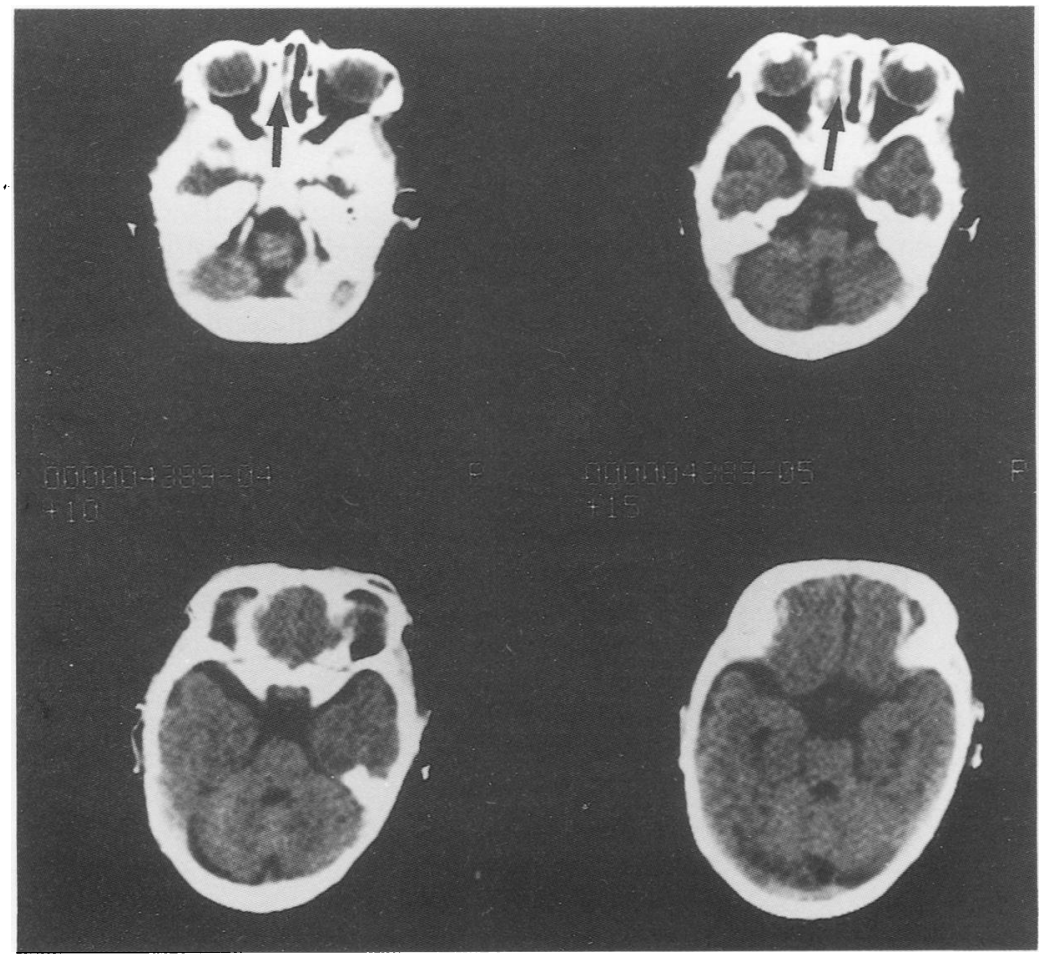

Figure 1 Transaxial computed tomograms showing opacification of the left ethmoid air sinuses (arrowed).

\section{Case report}

A girl, one of two surviving triplets, was born at 25 weeks' gestation with a birth weight of $620 \mathrm{~g}$. Immediately after birth she was intubated with a nasal endotracheal tube and was mechanically ventilated because of immature lungs. She received surfactant treatment but, because of a poor respiratory drive, required intermittent ventilation for the first 14 weeks of life. She was finally extubated 14 weeks after birth. During the period of ventilation she had to be reintubated on numerous occasions. Most of the intubations were carried out without difficulty, although it was recorded that four weeks after birth an endotracheal tube could not be passed through the left nostril. However, about eight weeks after birth a difficult intubation wascarried out through the left nostril but it was followed by a gush of clear fluid down the nose. Thereafter small amounts of serosanguineous fluid were seen dripping from the left nostril especially during bouts of crying or coughing. The fluid tested positive for glucose, indicating that it was cerebrospinal fluid (CSF). Fourteen weeks after birth the baby's condition deteriorated, she became irritable, and had a tense anterior fontanelle. A lumbar puncture was performed and yielded cloudy CSF with a white cell count of $2430 / \mathrm{ml}$. No bacteria were cultured, but she was diagnosed as having bacterial meningitis and was treated with antibiotics. The baby responded rapidly. After the attack of meningitis CSF continued to leak intermittently down the baby's left nostril and she was referred to the department of neurosurgery at Booth Hall Children's Hospital for management of the CSF fistula.

PHYSICAL EXAMINATION

The baby was admitted to the department of neurosurgery when she was two weeks past her expected date of delivery. On physical examination there were no abnormal findings except for an intermittent trickle of CSF out of the left nostril.

\section{INVESTIGATION}

Transaxial and coronal computed tomography of the brain was carried out. The transaxial scans showed opacification of the left sphenoid sinus and ethmoid air cells by a soft tissue mass (fig 1). Coronal scans confirmed the presence of soft material within the left sphenoid sinus and ethmoid air cells but there also appeared to be some tissue in the postnasal space. In addition the coronal computed tomograms 


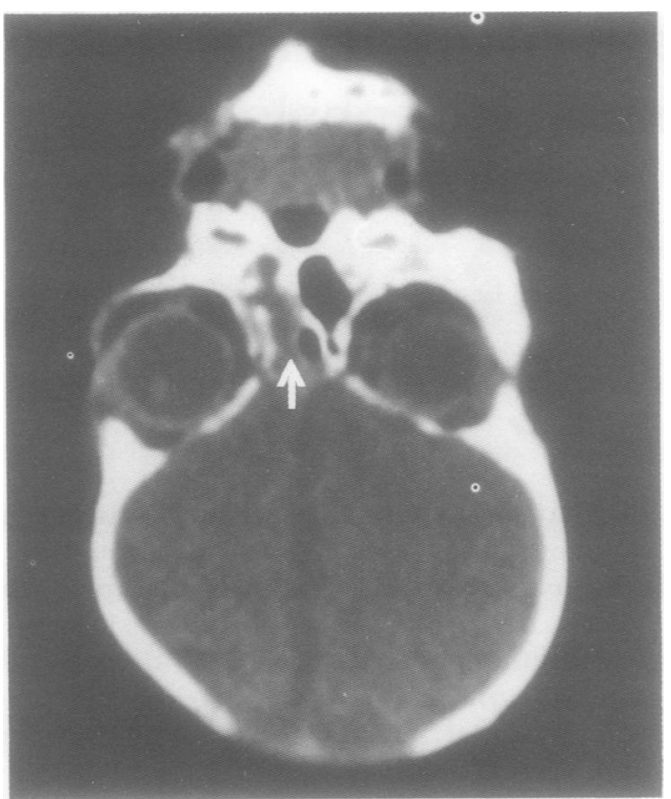

Figure 2 Coronal computed tomogram showing the defect in the left side of the cribriform plate (arrowed) and the soft tissue mass in the left ethmoid air sinus.

show a defect in the left side of the cribriform plate. Extending through the defect was a tongue of cerebral tissue that was in continuity with the soft tissue in the sphenoid sinus, ethmoid air cells, and postnasal space (fig 2). The appearances were compatible with the diagnosis of an intranasal sphenoethmoidal encephalocele.

\section{MANAGEMENT}

The baby was maintained on prophylactic antibiotic treatment until surgery was undertaken.

\section{OPERATION}

Fifteen weeks after her expected date of delivery the baby underwent surgery. A bicoronal scalp incision was made and an osteoplastic flap was turned based on the left temporalis muscle. The dura was opened parallel to the left supraorbital ridge and the left frontal lobe was retracted to expose the left side of the floor of the anterior cranial fossa. Under microscopic magnification a tongue of cortical tissue was seen extending through a $0.5 \mathrm{~cm}$ circular bony defect in the left side of the cribriform plate. The edges of the defect were well defined and lined by dura. The tongue of tissue was divided and similar material lying in the left ethmoid sinus was removed by suction. A sheet of pericranium was cut from the surface of the bone flap and laid over the bony defect. It was held in place with small pieces of fibrin mesh. The dura was closed, the bone flap was replaced and sutured into position, and the scalp was repaired.
The baby recovered rapidly from the procedure and no further leakage of CSF occurred from the nose.

\section{Discussion}

Nasal encephaloceles have been classified in a variety of ways. In Nager's classification they are included in the nasopharyngeal group, ${ }^{3}$ which is subdivided into transethmoidal, sphenoethmoidal, sphenonasopharyngeal, and basioccipital-sphenonasopharyngeal types. All of the encephaloceles in these groups have the common feature that they occupy the nasal cavity or are present in the nasopharynx. According to the Nagar classification our patient had a sphenoethmoidal encephalocele.

Nasal encephaloceles rarely spontaneously cause meningitis. ${ }^{1}$ Kohler et al describe a boy of 30 months with a nasal encephalocele who had recurrent attacks of bacterial meningitis unassociated with trauma. ${ }^{4}$ Lundorf et al reported a 28 year old woman who had had three attacks of meningitis and had a serous secretion from the nose for more than 10 years. ${ }^{5}$ To the best of our knowledge our patient with a nasal encephalocele is the first reported case of a CSF leak caused by the passage of a nasal endotracheal tube. Intubation is an obvious hazard in such cases but one that it is difficult to guard against due to the fact there are no external stigma of the condition. Clear or serosanguineous fluid dripping from the nose or running down the postnasal space after intubation should alert the attending medical staff to the possibility of the presence of a nasal encephalocele. Computed tomography provides a reliable and widely available method of visualising the lesion. However, it is not diagnostically conclusive to carry out transaxial scans alone; they will show the tissue in the sphenoid sinus, ethmoid air cells, and postnasal space but not the skull defect. To detect the skull defect it is necessary to carry out coronal scans as was shown in two cases by Lundorf et $a l^{5}$ and by us in our case. Magnetic resonance scanning also produces excellent images of nasal encephaloceles ${ }^{4}$ but we did not feel it was necessary to perform this examination in our patient as we had all the information we needed from the computed tomograms.

1 Dieber C, Dulac O. Cephaloceles: clinical and neuroradiological appearances. Neuroradiology 1983; 25: 199-216.

2 Lusk RP, Lee PC. Magnetic resonance imaging of congenital nasal masses. Otolaryngol Head Neck Surg 1986; 95: 303-6.

3 Nager GT. Cephaloceles. Laryngoscope 1987; 97: 77-84.

4 Kohler T, Wiedersberg H, Bollman L. Nasal encephalocele as a cause of recurrent bacterial meningitis. Monatsschr as a cause of recurrent bacterial

5 Lundorf E, Kjelddaard A, Halburt H. Coronal CT examination in the evaluation of small fronto-ethmoid encephaloceles. F Laryngol Otol 1988; 102: 1119-21. 